$\begin{array}{ll}\text { Abstracta Iranica } & \begin{array}{l}\text { Abstracta Iranica } \\ \text { Revue bibliographique pour le domaine irano-aryen }\end{array} \\ & \text { Volume } \mathbf{2 4} \text { | } \mathbf{2 0 0 3} \\ \text { Comptes rendus des publications de } \mathbf{2 0 0 1}\end{array}$

\title{
Culture and Conquest in Mongol Eurasia. Cambridge, Cambridge University Press, 2001, 245 p.
}

\section{Denise Aigle}

\section{(2) OpenEdition}

1 Journals

\section{Édition électronique}

URL : http://journals.openedition.org/abstractairanica/34374

DOI : 10.4000/abstractairanica.34374

ISSN : 1961-960X

Éditeur :

CNRS (UMR 7528 Mondes iraniens et indiens), Éditions de l'IFRI

\section{Édition imprimée}

Date de publication : 15 mai 2003

ISSN : 0240-8910

\section{Référence électronique}

Denise Aigle, "Culture and Conquest in Mongol Eurasia. Cambridge, Cambridge University Press, 2001, 245 p. », Abstracta Iranica [En ligne], Volume 24 | 2003, document 99, mis en ligne le 05 janvier 2010, consulté le 25 septembre 2020. URL : http://journals.openedition.org/abstractairanica/34374 ; DOI : https://doi.org/10.4000/abstractairanica.34374

Ce document a été généré automatiquement le 25 septembre 2020.

Tous droits réservés 


\title{
Culture and Conquest in Mongol Eurasia. Cambridge, Cambridge University Press, 2001, 245 p.
}

\author{
Denise Aigle
}

1 Dans cette monographie, l'auteur étudie la nature et les conditions dans lesquelles ont eu lieu les transferts culturels entre Yüan de Chine et Ilkhans d'Iran et comment ces deux dynasties ont su utiliser les ressources culturelles de leurs domaines respectifs dans leurs efforts pour se soutenir l'une l'autre.

2 Thomas Allsen a déjà livré dans le domaine des échanges culturels un ouvrage passionnant (Commodity and Exchange in the Mongol Empire: A Cultural History of Islamic Textiles, Cambridge, Cambridge University Press, 1997) ainsi que de nombreux articles («Two Cultural Brokers of Medieval Eurasia: Bolaq Aqa and Marco Polo», in : Michael Gervers and Wayne Schlepp, eds., Nomadic Diplomacy, Destruction and Religion from the Pacific to the Adriatic, Toronto, 1994, pp.63-78; «Ever Closer Encounters: the Appropriation of Culture and the Apportionment of Peoples in the Mongol Empire ", Journal of Early Modern History, vol. 1, (1997), pp. 2-23), pour ne citer que les plus récents.

3 L'auteur souligne que l'empire mongol peut être vu à la fois comme une «Pax Mongolica ", favorisant la circulation des hommes, les échanges et le commerce à longue distance et un « joug tatar », destructeur des cultures sédentaires. Dans ce livre Allsen démontre que cette vision manichéenne des choses est réductrice.

Les échanges culturels, sur une vaste échelle, ont été initiés par les Mongols euxmêmes; ils ont été les agents de la diffusion culturelle, le cas de Bolad Aqa en est l'un des plus significatifs. Minoritaires dans leur État, les Mongols ont fait un usage intensif de personnel étranger, sans liens politiques locaux, pour les aider à gouverner leurs vastes domaines. Les Yüan placèrent systématiquement des populations d'ethnies et de langues différentes, côte à côte, dans les chancelleries. Ces personnels ont été de formidables agents de transmission culturelle (voir le tableau de la page 6 qui témoigne de la grande mobilité des fonctionnaires dans tout l'empire). 
5 Après avoir posé le cadre historique (relations politiques et économiques entre les Yüan et les Ilkhans) l'auteur consacre la partie III de son ouvrage à décrire la carrière de Bolad Aqa, mongol de la tribu Dörben, que l'auteur considère comme un « intermédiaire » pour la diffusion culturelle. Le cœur de l'ouvrage est consacré à la description des échanges culturels dans plusieurs domaines: historiographie, géographie et cartographie, agriculture, cuisine, médecine, astronomie et peinture.

En conclusion l'auteur met en lumière des modèles et des méthodes dans les échanges culturels. Il constate que les marchandises de prestige circulaient en premier lieu; l'objectif premier des Mongols était de contrôler les sujets sédentaires, ce qui favorisa les contacts transculturels; les éléments qui sont entrés dans cette culture syncrétique étaient choisis selon les normes sociales et culturelles des Mongols; les Gengiskhanides ont su reconnaitre les talents humains, ils ont partagé ces talents comme une sorte de «butin» entre les membres de la famille impériale. Les cultures sédentaires ont été placées au centre comme le fait remarquer Thomas Allsen qui cite le cas des astronomes musulmans que les $Q a^{\prime} a n s$ ont fait venir en Chine. Mais si les Mongols avaient besoin de leurs connaissances, ce n'était pas pour des échanges scientifiques mais pour « lire les signes du ciel».

7 Voici un ouvrage important qui, à partir de matériaux très riches, jette un regard neuf et stimulant sur les échanges dans l'empire mongol. Dans le domaine des études sur l'empire mongol nous renvoyons également à Reuven Amitai-Preiss \& David Morgan, The Mongol Empire \& its Legacy, Leyde, Brill, 1999 (voir le c.r. dans Abs. Ir. 23, (2000), $\mathrm{n}^{\circ}$ 117).

\section{INDEX}

Thèmes : 4.1. Histoire médiévale

\section{AUTEURS}

DENISE AIGLE

IFEAD - Damas 